\title{
A DUPLA FACE DO TRABALHO INFANTOJUVENIL: a dialética entre o princípio educativo e o trabalho explorado ${ }^{1}$
}

\author{
Laura Souza Fonseca² \\ Luciana Francisca de Oliveira ${ }^{3}$
}

\begin{abstract}
Resumo
Este artigo é parte de uma pesquisa desenvolvida no Programa de PósGraduação da Faculdade de Educação da Universidade Federal do Rio Grande do Sul no período entre 2012-2014. Um dos objetivos de tal pesquisa foi compreender quais as concepções e as práticas sobre o trabalho infantojuvenil que apresentam algumas famílias beneficiárias do Programa Bolsa Família (PBF). Nesta escrita, trazemos uma reflexão acerca dos dados obtidos pela pesquisa, apoiando-nos no Materialismo Histórico Dialético como método de análise da realidade social em suas múltiplas determinações.
\end{abstract}

Palavras-chave: Trabalho infantojuvenil; Programa Bolsa Família; princípio educativo/exploração

\section{Resumen}

Éste artículo es parte de una investigación desarrollada en el Programa de Posgrado en Educación de la Universidad Federal del Rio Grande del Sur en el periodo comprendido entre 2012-2014. Uno de los objetivos de la investigación fue entender las concepciones y prácticas sobre el trabajo de niños y adolescentes de familias beneficiarias del Programa Bolsa Familia. Este artículo tiene como objetivo reflexionar sobre los datos obtenidos de la encuesta, basándose en el materialismo histórico dialéctico como el método de análisis de la realidad social y sus múltiples determinaciones.

Palabras llave: Trabajo de niños y adolescentes. Programa Bolsa Familia. Principio Educativo/Explotación

\footnotetext{
${ }^{1}$ DOI: https://doi.org/10.22409/tn.15i26.p9628

2 Pós-doutorado em Políticas Públicas e Formação Humana (PPFH/UERJ PDJ/CNPq) e em Estudios Latinoamericanos (UNAM/México EPD/CAPES). Professora Associada da FACED/UFRGS, área de EJA, Grupo Trabalho e Formação Humana (GTFH); E-mail: Isfonseca.Isf@gmail.com

${ }^{3}$ Psicóloga, mestre em Educação pelo Programa de Pós-graduação em Educação da Universidade Federal do Rio Grande do Sul. E-mail: lupsicosocial@gmail.com.br
} 
A dissertação intitulada "Pobreza, Trabalho Infantojuvenil e Escolarização: Concepções e Práticas a partir do Programa Bolsa Família" (Oliveira, 2014) desenvolvida no Programa de Pós-Graduação da Faculdade de Educação da Universidade Federal do Rio Grande do Sul no período entre 2012-2014, teve como um de seus objetivos compreender quais as concepções e as práticas sobre o trabalho infantojuvenil que apresentam algumas famílias beneficiárias do Programa Bolsa Família (PBF) e assistidas pelo Programa de Erradicação do Trabalho Infantil (PETI). A pesquisa partiu da atuação profissional da autora enquanto técnica de referência em um Centro de Referência Especializado da Assistência Social (CREAS), situado em um município da Região Metropolitana de Porto Alegre/RS. Utilizamos o estudo de caso como metodologia, tendo como instrumento de coleta de dados a análise documental de expedientes de famílias acompanhadas, bem como diário de campo, registros de grupos socioeducativos, reuniões, abordagens de rua e denúncias. A pesquisa mapeou ainda concepções e práticas de famílias beneficiárias e de educadoras/es acerca da infrequência e/ou evasão escolar.

Neste artigo, expomos alguns dados obtidos na pesquisa acerca da concepção de trabalho infantojuvenil apresentada pelas famílias, e trazemos algumas considerações levantadas a partir dos mesmos, apoiando-nos no Materialismo Histórico Dialético como método de análise da realidade social em suas múltiplas determinações.

Segundo Marx (2008), a realidade social se expressa como síntese relacional de múltiplas determinações historicizadas, sendo que o concreto é concreto porque é a síntese de múltiplas determinações, ou seja, unidade do diverso.

Partimos da concepção marxista de que os homens não são livres para escolher suas forças produtivas, porque estas são circunscritas pelas condições em que eles se encontram colocados e pelas forças produtivas adquiridas pela geração precedente.

Ao analisarmos a categoria trabalho, nos reportamos a Frigotto (1995), que sustenta que este é, por excelência, a forma pela qual o homem produz suas condições de existência, a história, o mundo propriamente humano, ou seja, o próprio ser humano. O trabalho, portanto, é o princípio educativo, sendo 
"fundamental que todo o ser humano, desde a mais tenra idade, socialize este pressuposto" (FRIGOTTO, 1995, p.31).

O trabalho, enquanto relação material de produção social da existência é fundante da especificidade humana. Pelo trabalho, o ser humano modifica a realidade que o circunda e modifica a si mesmo, alterando sua maneira de estar na realidade objetiva e de percebê-la.

No modo de produção capitalista, modo pelo qual atualmente estão organizadas as relações sociais de produção, a centralidade do trabalho como criador da condição humana recebe mediações que o transformam em alienação e mercadoria força de trabalho.

Buscamos apreender a categoria trabalho em sua dimensão ontológica, como mediação de primeira ordem (Mészáros, 2009) e, considerando o empírico da pesquisa, enunciamos determinações da exploração do trabalho, mediação de segunda ordem (Mészáros, 2009). Ou, na síntese de Frigotto (2002), apreendemos o trabalho pela sua dupla face; particularmente, na vida de crianças e adolescentes e na materialidade do fenômeno estudado.

Um dos limites do desenvolvimento capitalista é o da destruição dos postos de trabalho, o que gera a síndrome do desemprego estrutura $\beta$, a precarização e a flexibilização do trabalho vinculada à abolição dos direitos sociais duramente conquistados pela classe trabalhadora, bem como a ampliação da possibilidade de superexploração da força de trabalho.

A precarização, segundo Galeazzi e Holzmann (apud CATTANI, 2011) é definida como o processo de redução ou supressão de direitos laborais, decorrente da disseminação de formas de inserção no mercado de trabalho em substituição ao trabalho assalariado e às proteções a ele associadas. A noção de precarização do trabalho tem como parâmetro o regime de trabalho assalariado e se referencia na ausência ou redução de direitos e garantias do trabalho e a qualidade no exercício da atividade. Um movimento do capital para recuperação

\footnotetext{
${ }^{3}$ Aumento do excedente de trabalhadores, ou seja, a não necessidade, para a produção, de milhões de trabalhadores, em razão da diminuição dos postos de trabalho decorrentes do aumento da produtividade pela incorporação da microeletrônica e da nova base científico-técnica ao processo produtivo, significando assim, o aumento da miséria da fome e da barbárie social (Frigotto, 1996).
} 
da taxa de lucro, espoliando direitos conquistados pela luta da classe trabalhadora.

A reestruturação produtiva a partir dos anos 1970 provocou uma heterogeneidade nas formas de inserção ocupacional no mercado de trabalho, resultando na emergência do trabalho precário. Inscrevem-se neste âmbito as subcontratações como na condição de autônomo, terceirizações, trabalho por tempo determinado, contratação de estagiários e aprendizes, as quais acarretam perda das proteções legais e previdenciárias, conduzindo uma importante parcela de trabalhadores a uma situação de vulnerabilidade. (GALEAZZI e HOLZMANN, 2011, apud CATTANI). Em todos os casos, formas de trabalho que ampliam os lucros dos capitais, pela retirada de direitos trabalhistas, que resultaram de lutas classe.

A exploração do trabalho infantojuvenil também é uma forma precária de inserção no mercado de trabalho e que está associada à exploração do/a trabalhador/a adulto como um dos elementos que constituem o modo de produção capitalista e a consequente desigualdade social por ele produzida. Tal como coloca Fonseca (2009), ao apontar que a precariedade da vida do adulto provedor do sujeito de direitos, instituída pela ausência/insuficiência de políticas públicas de Estado, é o que afinal rouba a infância, e não o trabalho infantojuvenil em si.

A exploração do trabalho infantojuvenil, enquanto trabalho humano vivo e não formalizado, localiza-se dentro da divisão social do trabalho, constituindo uma das consequências bárbaras da acumulação do capital que se alimenta da exploração do trabalho. A materialidade disso se expressa no baixo custo dos produtos, jornada de duração indefinida, naturalização e invisibilidade de algumas formas de exploração como o trabalho doméstico, exploração sexual, tráfico de drogas, entre outros. Tais contradições enunciam a dupla face do trabalho - como organizador da vida do ser social e como exploração da mercadoria força de trabalho.

O trabalho enquanto valor de uso, por exemplo, no auxílio de tarefas domésticas é necessário, pois organiza a criança na medida em que o valor do trabalho vai compondo sua formação. O trabalho explorado, por sua vez, retira o seu tempo de estudo e sua energia vital é extirpada com a intensificação do trabalho. Isso fortalece um contingente grande de crianças e adolescentes 
sobrantes que acabam saindo da escola e ingressando no mundo do trabalho como estratégia de sobrevivência.

O trabalho infantojuvenil enquanto exploração da mercadoria força de trabalho produz subjetividades marcadas pelo desamparo social e, por consequência, afetivo e moral. Percebe-se a exclusão social concebida não como uma condição natural, mas como fruto de um processo histórico necessário à acumulação capitalista; que se reproduz através das gerações, numa perpetuação da precariedade das condições sociais materiais e morais que são fundantes da formação humana - marcas, a um só tempo, da exploração e da opressão. No entanto, há uma distorção, ou melhor, uma indiferenciação entre o trabalho como princípio educativo e como exploração na percepção das famílias e crianças que vivenciam o trabalho infantojuvenil e dos órgãos que se propõem a combatê-lo. Muitas crianças se submetem à exploração da sua força de trabalho e não entendem isso como violação de seus direitos. Simultaneamente, alguns adolescentes recusam o princípio educativo do trabalho e da partilha das tarefas domésticas, utilizando-se dos jargões que criminalizam o trabalho infantojuvenil, muito difundidos nas campanhas que se propõem a combatê-lo.

Fonseca (2009) compreende o trabalho como tensionado por uma dupla condição: produtor de valor de uso e produtor de valor. Na primeira condição, é princípio organizador da vida; na segunda, é materialidade de exploração/alienação. A autora explicita que o trabalho, categoria fundante do ser social, e cuja centralidade determina a vida humana, vem sendo (des) constituído. Nomeado de ajuda, utilizado de forma coercitiva em simulacro de trabalho educativo, organiza a vida para a precariedade desde tenra idade, porque mutila presente e futuro, não raro reproduzindo passados familiares, ou seja, potências (des) constituidoras do sentido do trabalho como valor de uso, porque transformam o trabalho educativo em subordinação. Isto porque, como trabalhadores precoces, estes sujeitos têm sua vida subordinada à exploração do capital, formando-se na opressão e espoliação em força maior do que nos laços socioafetivos (familiares, escolares, comunitários, culturais).

Tendo em vista a disputa de concepções acerca do trabalho, particularmente de sua dupla face, agravada em uma conjuntura que gira o princípio educativo para as formas de exploração, Fonseca (2013) analisa alguns materiais de divulgação de organizações governamentais e não governamentais

TrabalhoNecessario - www.uff.br/trabalhonecessario; Ano 15, № 26/2017 
que se propõem a erradicar/eliminar o trabalho infantil ${ }^{4}$. A autora faz um movimento de captura da temática trabalho infantil nestes materiais e cartilhas e tece algumas considerações. Em uma das cartilhas, o trabalho não aparece como princípio educativo, nem mesmo para as/os filhas/os da burguesia. O portador de texto ressalta a naturalização da ideia de trabalho como exploração, como tripalium $^{5}$, como castigo, como violência, fortalecendo o campo que propugna o fim da centralidade do trabalho. Além de escamotear o trabalho como organizador da vida, muitas destas publicações fazem a crítica por um viés moralizante que culpabiliza os pais. Em diversos materiais há uma minuciosa explanação sobre trabalho forçado, informal, mas em momento algum o trabalho aparece como formativo.

Além disso, há uma naturalização de que crianças e adolescentes devem ajudar em casa, o que permite pensar que a tarefa de organizar o lugar onde moram não compete a elas, que devem apenas ajudar o adulto a fazer o que é de sua (do adulto) responsabilidade. O princípio educativo da partilha dos afazeres nos lugares onde moramos, estudamos e trabalhamos não é mencionado (FONSECA, 2009). Defendemos que os afazeres domésticos não são tarefas exclusivas de adulto, mas responsabilidade de todos e todas, de acordo com a capacidade de cada um/a. Com isso, salientamos a necessidade de que sejam explicitadas as duas formas de trabalho infantojuvenil - como princípio educativo e como exploração. Perspectiva pela qual defendemos o combate à exploração da mercadoria força de trabalho infantojuvenil, e não a erradicação do trabalho infantojuvenil.

\footnotetext{
${ }^{4}$ Foram fontes da pesquisa da autora: (1) Programa Internacional para Erradicação do Trabalho Infantil (IPEC/OIT); (2) Fundo das Nações Unidas para a Infância (UNICEF/ONU); (3) Fórum Nacional de Prevenção e Erradicação do Trabalho Infantil (FNPETI); (4) Fórum Estadual de Prevenção e Erradicação do Trabalho Infantil e Proteção do Trabalho Adolescente/RS (FEPETI/RS); (5) Central Única dos Trabalhadores (CUT); (6) Central dos Trabalhadores e das Trabalhadoras do Brasil (CTB); e (7) Rede Promenino da Fundação Telefônica/Vivo.

${ }^{5}$ Do latim "tripalium", palavra que denominava um instrumento de tortura que consistia em um gancho de três pontas, cuja função era a evisceração ou a retirada e exposição das tripas, região de intensa dor, causando lenta agonia. Foi criado e utilizado durante a Inquisição. Do termo originou-se a palavra "trabalho". (BONZATTO, 2013).
} 


\section{Discussão acerca das concepções e práticas familiares sobre o trabalho infantojuvenil}

A pesquisa encontrou como resultados as seguintes concepções sobre 0 trabalho infantojuvenil nas famílias estudadas, ideias que discutiremos em seguida:

- Atribuição do trabalho da criança ou adolescente ao seu desejo individual;

- O trabalho infantojuvenil é percebido como ajuda diante da impossibilidade dos adultos de proverem o sustento da família;

- O trabalho infantojuvenil é utilizado como estratégia para a criança não ficar pela rua, embora o trabalho de muitos seja na própria rua; trabalho concebido como forma de ocupação para as crianças/adolescentes;

- Trabalho como ocupação e formação, enquanto parte de uma moral trabalhista;

- O acompanhamento da criança no trabalho adulto ocorre para que estes não fiquem em casa sozinhos e/ou porque não possuem um local para deixá-los enquanto trabalham;

- Descrença na cultura de direitos da criança e do adolescente;

- Concepção negativa quanto à proibição do trabalho infantil;

Uma das constatações da pesquisa foi de que há uma percepção por parte dos adultos das famílias estudadas, de que 0 trabalho realizado pela criança/adolescente é fruto de um desejo/necessidade deste/a de comprar itens para si, tais como objetos, comidas, roupas e lazer, itens que os adultos geralmente não podem prover. Nos discursos suscita uma ideia de que as crianças trabalham porque tem vontade de adquirir itens para si, não havendo uma distinção entre desejo e necessidade. Indaga-se, com isso, se os itens mencionados pelas famílias (calçado, brinquedos, jogos, comidas e bebidas), traduzidos como vestuário, lazer e alimentação, não estariam no âmbito do direito e não como itens supérfluos ou extraordinários.

Conforme o Estatuto da Criança e do Adolescente (ECA) é dever da família, da comunidade, da sociedade em geral e do poder público assegurar, 
com absoluta prioridade, a efetivação dos direitos referentes à vida, à saúde, à alimentação, à educação, ao esporte, ao lazer, à profissionalização, à cultura, à dignidade, ao respeito, à liberdade e à convivência familiar e comunitária. Direitos fundamentais os quais devem permitir "o nascimento e o desenvolvimento sadio e harmonioso, em condições dignas de existência" (BRASIL, 1990). Importa colocarmos atenção no ordenamento de quem deve prover os direitos das crianças e adolescentes, ao iniciar pela família. O ECA (como o Art. 227 da Constituição Federal que o embasa) retira a responsabilidade do Estado de garantir, pelo investimento do fundo público, as condições necessárias para que as famílias da classe trabalhadora assegurem a reprodução da vida.

As falas que sustentam a existência de um querer por parte das crianças vêm acompanhadas do anúncio da impossibilidade do adulto de prover suas necessidades em razão da insuficiência de recursos. Bebel et al (1980) colocam que, infelizmente, para muitas famílias, serve de alento 0 ato de saber que rapidamente seus filhos estarão prontos para adquirir o valor de instrumentos de trabalho e em certa medida, cobrirão os gastos de sua manutenção.

Assim, o trabalho infantojuvenil é admitido como forma de contribuir com a renda familiar ou ainda para que a criança possa suprir suas próprias demandas. E novamente na imprecisão da dupla face - a ajuda - aparece tanto na partilha das tarefas de casa como na composição da renda da família - neste caso sugerindo duas trabalhadoras pelo preço de uma, normalmente as gurias cuidando da casa e/ou de irmãs/os mais novas/os para que a mãe vá trabalhar ou buscar emprego.

Constata-se que a insuficiência da renda familiar é utilizada como argumento para justificar o trabalho de crianças e adolescentes. De acordo com a Constituição Federal de 1988, em seu artigo sétimo, o salário mínimo6 , fixado em lei, nacionalmente unificado, é um direito dos trabalhadores urbanos e rurais, devendo ser capaz de:

[...] atender a suas necessidades vitais básicas e às de sua família com moradia, alimentação, educação, saúde, lazer, vestuário, higiene, transporte e previdência social, com reajustes periódicos

\footnotetext{
${ }^{6} \mathrm{O}$ salário mínimo é fixado pela jornada integral de 8 horas diárias de trabalho ou 44 horas semanais. Pode ser reduzido para trabalhadores com jornada parcial. (BRASIL, CF, 1988, art. 7․ Disponível em: <http://www.planalto.gov.br/ccivil_03/constituicao/constitui cao.htm>. Acesso em: $18 \mathrm{dez} 2014$.
} 
que Ihe preservem o poder aquisitivo, sendo vedada sua vinculação para qualquer fim (BRASIL, CF, 1988, art. $7^{\circ}$ ).

A Consolidação das Leis Trabalhistas conceitua o salário mínimo como:

[...] a contraprestação mínima devida e paga diretamente pelo empregador a todo trabalhador, inclusive ao trabalhador rural, sem distinção de sexo, por dia normal de serviço, e capaz de satisfazer, em determinada época e região do País, as suas necessidades normais de alimentação, habitação, vestuário, higiene e transporte. (BRASIL, 1943, 2014, art. 76)

O DIEESE ${ }^{7}$ faz um comparativo entre os valores do salário mínimo e do salário mínimo necessário, cujos valores, no período de novembro de 2014 , foram respectivamente de $R \$ 724,00$ e $R \$ 2.923,22$. O Salário Mínimo Necessário é calculado mensalmente pelo DIEESE, levando em consideração o preceito constitucional que diz que o salário mínimo deve ser capaz de suprir as necessidades básicas de um trabalhador e de sua família com moradia, alimentação, educação, saúde, lazer, vestuário, higiene, transporte e previdência social. A família considerada é de dois adultos e duas crianças, que, juntas, consomem como um adulto.

Nas famílias pesquisadas constatou-se que o orçamento doméstico não comporta o valor necessário ao provimento das necessidades. À discussão do salário mínimo, o qual é inferior à possibilidade de sustento de uma família, somase a ideia de renda mínima, propagada pela Política Nacional de Assistência Social e materializada no Programa Bolsa Família. Desloca-se, portanto a discussão pela garantia de um salário mínimo que dê conta das necessidades de uma família, para a ideia de "renda mínima", cujos valores estão aquém do salário mínimo constitucional. Desloca-se a centralidade do trabalho como modo de produção e reprodução da vida para a pobreza como determinante da desigualdade social, e proliferam políticas de alívio à pobreza - a bolsificação da vida.

E mais, na medida em que os adultos não conseguem obter recursos necessários para a sobrevivência, os infantes acabam ingressando em um mercado de trabalho informal e ilegal, tornando-se, desde cedo, vítimas da

\footnotetext{
7 DEPARTAMENTO Intersindical de Estatística e Estudos Socioeconômicos (DIEESE). Salário mínimo nominal e necessário. Disponível em < http://www.dieese.org.br/analisecestabasica/salarioMinimo.html > Acesso em 20 Dez 2014.
} 
precarização do trabalho. Em condições insalubres, crianças, adolescentes e adultos são expostos a riscos de contrair doenças, atropelamentos, bem como todas as doenças decorrentes da sobrecarga de trabalho. $O$ trabalho destes adultos na maioria das vezes é precarizado e informal, tais como guardar carros, pedir esmolas na sinaleira, recolher lixo reciclável em carroças ou carrinhos.

A pesquisa concluiu que as famílias concebem o trabalho infantojuvenil como uma necessidade de complementação da renda familiar, que se mostra insuficiente para atender as necessidades dos filhos. Entendemos que tal prática configura uma violação dos direitos fundamentais, que devem garantir a vida em condições dignas de existência. Sob o sistema capitalista, os filhos são para a família proletária uma carga pesada e insustentável. Além disso, o salário reduzido, a insegurança no trabalho e até a fome frequentemente convertem uma criança em um pequeno trabalhador.

Outra concepção sobre o trabalho infantojuvenil pelos adultos pesquisados foi de que o trabalho serve como ocupação dos filhos, pois assim ficam protegidos contra a ociosidade e contra o risco do envolvimento com o uso ou tráfico de drogas, que também constitui uma fonte de renda para os filhos da pobreza. Cabe lembrarmos, no entanto, que o tráfico de drogas é considerado uma das piores ${ }^{8}$ formas de trabalho infantojuvenil e talvez uma das mais difíceis de combater.

Em muitos casos, observamos nos históricos de alguns jovens encaminhados para cumprirem medida socioeducativa que estes trabalhavam desde crianças e foram "migrando" para formas de trabalho que lhes conferissem renda de forma mais imediata como o tráfico de drogas, ainda que estas the oferecessem maior risco de morte.

O envolvimento com o tráfico de drogas, colocado pela moral burguesa como um caminho "escolhido" pelos jovens da periferia, talvez seja uma alternativa possível para o usufruto dos "modos de gozo próprios do modelo econômico neoliberal" (ROSA, 2002), já que as possibilidades de ganhar a vida com o próprio esforço estão limitadas pela desigualdade de condições sociais,

\footnotetext{
${ }^{8}$ A Convenção 182, de 1999, foi ratificada pelo Brasil em 2000; dispõe sobre a Proibição das Piores Formas de Trabalho Infantil e Ação Imediata para sua Eliminação (ORGANIZAÇÃO INTERNACIONAL DO TRABALHO, 2013)
} 
morais e afetivas. O filme Notícias de uma Guerra Particular ${ }^{9}$ traz alguns relatos de meninos que ingressam no tráfico de drogas em razão da necessidade de suprir as lacunas do Estado nas comunidades pobres (direitos sociais não garantidos), além da necessidade de reconhecimento e valorização, o que não é encontrado em outras fontes.

Observou-se que estes adultos repetem a moral burguesa para a qual, às/aos filhas/os da classe trabalhadora não podem ficar sem trabalhar porque "cabeça vazia, oficina do diabo"; não raro, são taxados de vagabundos ou desocupados ou, ainda, que estão na condição de pobreza porque não querem trabalhar. Assim, reproduz-se o mito da classe trabalhadora desocupada, sendo que o ócio só é "permitido" às/aos filhas/os da burguesia. Trotsky (2006) nos ajuda a pensar quando refere que a eficácia de preceitos morais universais é muito limitada, pois as normas "obrigatórias para todos" são tanto menos eficazes quanto mais áspera se torna a luta de classes. A burguesia, cuja consciência de classe é superior (pela sua coesão e intransigência) à do proletariado, tem interesse vital em impor a sua moral às classes oprimidas. As normas concretas da burguesia são mascaradas com a ajuda de abstrações morais sob a égide da religião, da filosofia ou do "bom senso". No plano ideológico, as normas morais obrigatórias para todos, assim como a categoria trabalho, adquirem um conteúdo de classe, constituindo, portanto, uma construção social.

Ainda que exista uma confusão entre 0 trabalho explorado e 0 trabalho como princípio educativo, a pesquisa mostra que alguns tipos de trabalho são menos aceitáveis que outros. Por um lado condenam a exploração sexual e comercial, o tráfico de drogas e a mendicância, mas naturalizam o trabalho doméstico e domiciliar (Fonseca, 2015) em vendas e catação de materiais recicláveis ou ainda quando as crianças apenas acompanham o trabalho dos pais. Há também uma indistinção entre a exploração do trabalho doméstico e partilha das tarefas de casa, justificado pelo fato de que a maioria deles (adultos) trabalhou quando criança.

Entendemos que esta naturalização desconsidera outros aspectos da formação humana (escola, lazer, brinquedo, tempo livre, arte, cultura,

\footnotetext{
${ }^{9}$ NOTÍCIAS de uma guerra particular. Direção: João Moreira Salles e Kátia Lund. Rio de Janeiro, Videofilmes,1999. DVD, 57 min.
} 
adolescência), os quais sofrem uma espécie de apagamento em detrimento dos imperativos de sobrevivência. O imperativo da sobrevivência e, paradoxalmente, o do consumo vêm constituindo as subjetividades destas crianças/adolescentes, particularmente das famílias pobres.

Rosa (2002) nos alerta que devemos levar em consideração o lugar que ocupa o sujeito na estrutura social, ou seja, na lógica discursiva do mercado, para que se consiga detectar as sutis malhas da dominação e a não confundir seus efeitos com o que é próprio do sujeito. Aponta que a apatia, a solidão e o emudecimento, assim como a reprodução, na subjetividade, da violência e da pobreza afetiva e intelectual, produz no sujeito um efeito de resto.

Estes efeitos se reproduzem nas subjetividades e se perpetuam nas gerações posteriores. Nas infâncias destes adultos, muito comum era que uma criança pobre, do sexo feminino e ainda muito pequena, saísse de casa para trabalhar em casa de famílias ricas realizando todas as tarefas domésticas, além de cuidar dos filhos, em troca de abrigo e comida. Numa perspectiva de classe, vemos que às crianças pobres destina-se o trabalho que garanta sua própria sobrevivência e sirva aos ricos, ao passo que às/aos filhas/os da burguesia reserva-se o estudo, o lazer e a alimentação.

$\mathrm{Na}$ perspectiva de gênero, percebe-se ainda a banalização do trabalho doméstico, como se toda menina pobre estivesse predestinada a tomar conta da casa e das/os irmã/os e depois trabalhar como doméstica, afinal, este foi o seu aprendizado.

Vemos que, atualmente, o capitalismo impôs à mulher que esta saísse do lar para engrossar a fila do desemprego, o que serve à manutenção da acumulação. Aliado a este interesse capitalista, soma-se a impossibilidade de sobrevivência com o salário de apenas um membro da família, sobrecarregando a mulher com o trabalho doméstico, cuidados com filhas/os e ainda o trabalho assalariado.

A mulher é lançada ao mercado de trabalho, mas em um contexto de degradação das condições de trabalho, somado à desvalorização do trabalho doméstico. As crianças também acabam sofrendo o ônus destas mudanças. Às meninas, resta a obrigação da tarefa não valorizada e não remunerada do cuidado com a casa e com outras crianças ou ainda como objeto de exploração sexual.

TrabalhoNecessario - www.uff.br/trabalhonecessario; Ano 15, № 26/2017 
Fica uma questão: a quem se outorga o dever do trabalho doméstico e do cuidado e educação com as crianças, especialmente as/os filhas/os do proletariado? Trotsky (apud Bebel et al, 1980) defende a socialização do trabalho doméstico e da educação. Fraser (2009) defende uma forma de vida que descentralize $o$ trabalho assalariado e valorize as atividades desmercantilizadas, como o trabalho de cuidar, o qual é socialmente necessário.

Junto à ideia do trabalho infantojuvenil como forma de ocupação e a consequente reprodução na vida familiar e cotidiana das múltiplas violências e violações de direitos sofridas, prevalece uma concepção negativa da proibição do trabalho infantojuvenil. A pesquisa apontou que tanto as famílias como a escola reproduzem o discurso do trabalho de crianças e adolescentes como ocupação, prescrevendo 0 trabalho infantojuvenil sem observar outras possibilidades educativas.

Tais constatações refletem as contradições sociais sentidas principalmente pelas pessoas que estão em lugar social marginalizado na engrenagem capitalista. As famílias pobres são exigidas quanto à proibição de bater nos filhos, sendo que o aparelho repressor policial tem autorização para espancá-los e não respeitá-los como sujeito de direitos. Estas falas nos remetem às reflexões de Scheinvar (2009), que destaca como um exemplo de criminalização das famílias pobres a prática do Conselho Tutelar, que opera no sentido da judicialização da vida, muitas vezes sob a forma de prescrição de normas e castigos, no intuito de garantir a lei.

É facilmente observável que a lei não vale para todos. Percebemos que a garantia dos direitos fundamentais não é cumprida quando se trata da população pobre. No entanto, a ela reserva-se o cumprimento à risca do direito penal, testemunhado nas formas de combate à pobreza hoje vigentes. O controle, o disciplinamento e a criminalização dos pobres como manutenção da estrutura social tem sido uma prática constante não somente pela polícia, mas legitimada por uma rede de equipamentos da assistência social, saúde, educação, conselho tutelar, entre outros.

A pesquisa observa ainda, nas famílias estudadas, outras contradições que demarcam suas existências indignas. As mulheres, que são na maioria das vezes as pessoas de referência de tais famílias, acumulam a dupla responsabilidade de sustento e cuidado com os filhos. A lei proíbe que os filhos sejam deixados

TrabalhoNecessario - www.uff.br/trabalhonecessario; Ano 15, № 26/2017 
sozinhos em casa, proíbe o trabalho infantil ou que os mesmos acompanhem os pais no trabalho; contraditoriamente, as políticas não garantem o acesso à educação em tempo integral nem trabalho decente, nem salário necessário à manutenção da família. Sendo assim, quem se encontra nestas condições, e que não acessaram a educação (ou que dela foram expulsas), ficam sem alternativas.

As famílias atendidas pela assistência social vivenciam o dilema entre a necessidade de gerar renda para sustentarem seus filhos e a ausência de uma alternativa de local para deixá-los enquanto trabalham. Somado a isso, faltam vagas na educação infantil e nas escolas de turno integral, levando muitas mulheres a submeterem-se a trabalhos precarizados e dependendo de "benefícios" assistenciais para sobreviver.

$\mathrm{Na}$ falta de uma rede de apoio familiar que possa auxiliar no cuidado com os filhos, o ônus do cuidado se torna alto, geralmente maior do que a renda, considerando a baixa escolaridade que dificulta as possibilidades de trabalho. Este contexto frequentemente acaba forçando o reordenamento das tarefas domésticas, em que o cuidado com as crianças e com a casa é assumido pelas crianças mais velhas. Assim, o trabalho precoce vai tomando a forma de exploração, uma vez que ele vai acontecendo quase naturalmente pelo deslizamento gradual da criança da escola para o trabalho.

Entre a eventual catação de uma latinha daqui ou dali para comprar um pão ou entre uma e outra falta à escola pra cuidar dos irmãos, a criança vai iniciando precocemente no mundo do trabalho alienado, o qual prolonga-se por sua adolescência e vida adulta. A precarização do trabalho deste adulto que nunca vivenciou um trabalho decente, assim como a falta de um sentido mais imediato do processo de escolarização, sinalizam a transgeracionalidade do ciclo da pobreza.

Retomamos aqui as discussões em torno da superexploração e da produção de sobrantes. Tais questões socioeconômicas têm suas repercussões na função protetiva da família, a qual se choca diretamente com a desproteção estatal em relação aos cidadãos em condições de miséria, escolaridade inconsistente, incapacidade de provisão do sustento e dependência de bolsas para sobrevivência.

As múltiplas violações de direitos sofridas fragilizam as famílias para o exercício da parentalidade enquanto proteção e provimento das necessidades de

TrabalhoNecessario - www.uff.br/trabalhonecessario; Ano 15, № 26/2017 
crianças e adolescentes, uma vez que precisam desempenhar esta função dentro das condições materiais insuficientes para se viver.

A proteção à criança, dever de todos, quando exercida no âmbito da família, fica prejudicada por conta de uma série de fatores que geram a fragilização dos vínculos, dentre eles o desamparo pela não garantia de exercício dos direitos fundamentais condizentes com uma vida digna.

Entretanto, quando o Estado deixa de cumprir o dever na proteção no que Ihe cabe, ou seja, garantir direitos, podemos considerá-lo omisso e negligente? $O$ ECA prevê responsabilidades mútuas entre família, escola e Estado na efetivação dos direitos de crianças e adolescentes, porém, há uma ênfase na responsabilidade parental.

Quando trata das Medidas Específicas de Proteção aplicadas pela autoridade competente, por exemplo, estas são voltadas aos pais, sem, portanto, mencionar algum tipo de punição ou responsabilização ao Estado no caso de violação de direitos à criança ou ao adolescente. As autoridades competentes, Conselho Tutelar e Poder Judiciário, acabam não sendo fiscalizadas ou responsabilizadas nos casos em que ferem os direitos estabelecidos no ECA.

Quando se trata de garantir direitos é necessário que tenhamos a preocupação em como punir, a quem punir e quem punir. As políticas sociais adotadas pelo Estado tais como PBF e PETI, não problematizam a existência de uma produção da desigualdade social, sendo que os resultantes desta serão tratados/remediados pelo aparelho de Estado através de políticas compensatórias e/ou criminalizantes.

No caso da proteção social a ser afiançada pela PNAS, se faz necessário ampliarmos o entendimento sobre como se produz a demanda por proteção, quem é o sujeito da proteção e qual a forma de exercê-la.

Tais concepções nos ajudam a entender que a realidade destas famílias é parte de uma estrutura social marcada por uma lógica que favorece a exclusão necessária à acumulação capitalista e cronifica a desigualdade social. Percebe-se também a fragilidade das conquistas da legislação e das políticas públicas de Estado. A materialidade da vida da classe trabalhadora revela a grande distância entre o direito tal como está posto e o cotidiano de muitas famílias que se ajustam a formas específicas de sobrevivência, dentre elas o trabalho infantojuvenil explorado.

TrabalhoNecessario - www.uff.br/trabalhonecessario; Ano 15, №26/2017 


\section{Considerações finais}

A infância e a adolescência enquanto etapas do desenvolvimento humano passível de investimentos como arte, cultura, esporte, lazer, educação foram devidamente apropriadas apenas para as/os filhas/os da burguesia. Ao analisarmos a materialidade da vida das famílias que não dispõem de condições dignas de existência, constata-se que as violações dos direitos fundamentais preconizados na Constituição Federal, afetam diretamente os laços familiares, o exercício da parentalidade e o rompimento do ciclo da pobreza. As diversas formas de 'ocupar' o tempo infantojuvenil estão diretamente ligadas ao acesso às mínimas condições materiais de existência, tais como o direito à saúde, educação, moradia, trabalho etc.

A ausência de materialidade da criança e o do adolescente como sujeito de direitos e sua condição peculiar enquanto ser em desenvolvimento, bem como a repetição dos padrões vividos nas infâncias dos adultos, marcadas pelo início precoce no mundo do trabalho em detrimento do acesso/permanência e conclusão com qualidade na escola e em espaços socioeducativos, mostra múltiplas violações de direitos sofridas desde a tenra idade e que se perpetua nas gerações posteriores. O descontentamento com as políticas de proteção e defesa da criança são um reflexo de sua inoperância, no sentido de proporcionar alternativas às famílias que têm a exploração do trabalho de suas/seus filhas/os como estratégia de ocupação e sobrevivência material.

O trabalho infantojuvenil realizado como forma de garantir sobrevivência é, portanto, uma forma de trabalho explorado. Há um conjunto de condições sociais e materiais degradantes, além de aspectos culturais, como causas que levam estas famílias a inserirem crianças e adolescentes no trabalho explorado. Ou seja, a exploração do trabalho infantojuvenil não é uma opção, e sim constitui um fenômeno social de múltiplas determinações.

O trabalho como formador do humano, num contexto de vulnerabilidade social, corre o risco de tomar a dimensão de exploração, devido à precariedade das condições materiais de sobrevivência. A centralidade do trabalho como criador da condição humana, recebe mediações que transformam o trabalho criador em alienação, mercadoria e força de trabalho. Há que se problematizar a diferença entre ajuda e exploração, pois tal contradição enuncia a concomitância das duas faces do trabalho (como organizador da vida do ser social e como 
exploração da mercadoria força de trabalho). Neste sentido, o que se pretende erradicar é a exploração do trabalho infanto-juvenil. Não basta criminalizar as práticas de trabalho infantojuvenil sem que sejam pensadas as raízes da questão, e suas determinações históricas, culturais e políticas.

O fenômeno do trabalho infantojuvenil explorado possui determinações estruturais e conjunturais, as quais possuem implicações nas subjetividades e nos modos de organizações familiares. Constatamos uma estrutura de permanente violação de direitos, em que problemas sociais resultantes do modo de produção capitalista são individualizados e se tornam alvo de políticas compensatórias e ordens criminalizantes. Esta engrenagem perpetua a desigualdade social favorecendo a acumulação capitalista em detrimento de uma classe cada vez mais apartada da esfera dos direitos sociais.

A divisão de classes e a nítida desigualdade social que caracteriza nossa sociedade capitalista nos apontam para determinações estruturais. Não obstante, de forma recorrente, localizamos tais determinações exclusivamente nas individualidades ou em núcleos familiares, o que não tem nos ajudado na compreensão do fenômeno nem tampouco no rompimento de sua continuidade.

Há uma tendência, própria do ideário neoliberal, que associa as defasagens escolares e a evasão escolar a uma "escolha" pessoal ou a alguma deficiência pessoal ou familiar. Isso significa o deslocamento da responsabilidade social para o plano individual - culpabilizando vítimas da desigualdade social. Tais ideias são reafirmadas por uma consciência alienada de que os vencedores ou os incluídos devem seu sucesso ao seu esforço e competência - reificando a meritocracia; enquanto os excluídos, os miseráveis do mundo pagam o preço de sua incompetência ou de suas escolhas - como se, de fato, as condições materiais de existência não compusessem as determinações das possibilidades desta mesma existência humana.

Retomando a perspectiva de Marx (1982; 2008), consideramos que a realidade social, composta por relações sociais e econômicas, é ordenada por uma estrutura de classes e não por uma escolha individual. A solução da crise da organização familiar e da educação fica, portanto, condicionada à superação do capitalismo e à socialização dos meios de produção, das funções e dos serviços de forma completa. 
Por vezes ainda contribuímos para sua perpetuação, ao reproduzirmos enunciados moralistas que depreciam a classe trabalhadora em favor da acumulação capitalista. Pensamos que esta reprodução quase sempre se naturaliza em nossos discursos e práticas sem que percebamos, uma vez que está espalhada no tecido social como verdade absoluta.

Acreditamos em avanços possíveis por processos formativos que ampliem nossa compreensão acerca dos mecanismos que engendram as subjetividades e as relações sociais das quais compartilhamos. Dar-se conta de que nada é por acaso, que a desigualdade social não é algo natural ou individual, já é um passo para nos colocarmos em luta por um mundo em que todos tenham a garantia de condições dignas de existência. Ou, na belíssima síntese de Rosa Luxemburgo "Por um mundo onde sejamos socialmente iguais, humanamente diferentes e totalmente livres".

Entendemos que a reflexão produzida nesta pesquisa contribui com os diversos espaços em que a questão dos direitos do infantojuvenil estejam colocados como objeto de trabalho e de estudo. Estes espaços, atravessados por inúmeras contradições que impedem a garantia da proteção a este sujeito, carecem de maior aprofundamento acerca da compreensão dos fenômenos que caracterizam as violências e violações por ele sofridas, elaboração fundamental para a proposição e avaliação de políticas sociais, de Estado e de governo.

\section{Referências}

BEBEL, August et al. Da velha à nova família. São Paulo: Proposta Editorial, 1980.

BRASIL, Lei № 8.069 de 13 de julho de 1990. Estatuto da Criança e do Adolescente.

FONSECA, Laura Souza. Apoio socioeducativo, enraizamento do infanto-juvenil? (com) vivências em comunidades da periferia urbana. Cadernos de Educação. Pelotas: FaE/PPGE/UFPel, janeiro/abril 2009.

FONSECA, Laura S. Trabalho e políticas sociais no tempo infantojuvenil: concepções e práticas no Brasil [e no México]. Relatório PDJ/CNPq. Rio de Janeiro, abril 2013. Inédito.

FONSECA, Laura S. Trabalho Infantojuvenil: notas sobre concepções e práticas. Revista Teias v. 16, n. 40, p. 204-221, (2015): Diferenças e Educação. 
FRASER, Nancy. O feminismo, o capitalismo e a astúcia da história. Mediações, Londrina, v. 14, n.2, p. 11-33, Jul/Dez. 2009.

FRIGOTTO, Gaudêncio. Educação e crise do capitalismo real. São Paulo: Cortez, 1995.

FRIGOTTO, Gaudêncio. A dupla face do trabalho: criação e destruição da vida. In: FRIGOTTO, G.; CIAVATTA, M. (Orgs.) A experiência do trabalho e a educação básica. Rio de Janeiro, DP\&A, 2002.

GALEAZZI, Irene. HOLZMANN, Lorena. Precarização do trabalho. In: CATTANI, A.; HOLZMANN, L. (Orgs.) Dicionário de trabalho e tecnologia. 2.ed. Porto Alegre: Zouk, 2011. p.259- 265.

MARX, Karl. Contribuição à crítica da economia política. Tradução e Introdução de Florestan Fernandes. 2.ed. São Paulo: Expressão Popular, 2008.

MARX, Karl. O Capital (7ª edição). Rio de Janeiro: LTC, 1982.

MÉSZÁROS, I. Para além do capital. São Paulo, Boitempo, 2009.

ROSA, Mirian Debieux. Uma escuta psicanalítica das vidas secas. Revista de Psicanálise Textura n.2, 2002.

SCHEINVAR, Estela. O feitiço da política pública. Escola, sociedade civis e direitos da criança e do adolescente. Rio de Janeiro: Lamparina, 2009.

NOTÍCIAS de uma guerra particular. Direção: João Moreira Salles e Kátia Lund. Rio de Janeiro, Videofilmes,1999. DVD, $57 \mathrm{~min}$.

ORGANIZAÇÃO INTERNACIONAL DO TRABALHO. Convenção $\mathbf{N}^{\circ}$ 182. Sobre Proibição das Piores Formas de Trabalho Infantil e Ação Imediata para sua Eliminação. Disponível em: < http://www.oitbrasil.org.br/node/518>. Acesso em 13 Dez 2013.

TROTSKY, Leon. A moral deles e a nossa. Marxismo Vivo, local, n.13, p. 63-73, 2006.

TROTSKY, Leon. Escritos sobre a Questão Feminina. In: BEBEL, August et al. Da velha à nova família. São Paulo: Proposta Editorial, 1980.

Recebido em: 24 de junho de 2016 Aprovado em: 19 de janeiro de 2017 Pubicado em: 4 de junho de 2017 